\title{
Insensitivity versus poor response to tumour necrosis factor inhibitors in rheumatoid arthritis: a retrospective cohort study
}

Sae Ochi ${ }^{1,2^{*}}$, Kazuyoshi Saito ${ }^{2}$, Fumitaka Mizoguchi ${ }^{3}$, Shigeaki Kato ${ }^{4}$ and Yoshiya Tanaka ${ }^{2}$

\begin{abstract}
Background: With advancement in the treatment options of rheumatoid arthritis (RA), optimising the outcomes of difficult-to-treat patients has become increasingly important in clinical practice. In particular, insensitivity to first-line biologic disease-modifying anti-rheumatic drugs (bDMARD) is becoming a significant problem because it may decrease the treatment adherence of patients. This study aimed to compare RA patients with an insensitivity and those with a poor response to initial treatment with tumour necrosis factor inhibitors (TNFis), which are the most frequently used bDMARDs.
\end{abstract}

Methods: This is a retrospective cohort study using clinical data from the FIRST registry. bDMARD-naïve RA patients treated with tumour necrosis factor inhibitors (TNFis) from August 2003 to May 2019 were included and categorised into three groups: TNFi insensitivity, poor response to TNFis and controls. TNFi insensitivity was defined as follows: (1) discontinuation of TNFi treatment within 22 weeks due to lack of any response, or (2) an increase in the disease activity score in 28 joints-C-reactive protein (DAS28-CRP) of $>0.6$ at week 22 compared with week 0 . Among the remaining patients, those with a DAS28-CRP > 2.6 at week 22 were categorised in the poor response group.

Results: Of the included patients, 94 were classified in the insensitivity, 604 in the poor response and 915 in the control. A higher DAS28-CRP before treatment was a risk factor for a poor response but not for insensitivity. In contrast, dose escalation of infliximab decreased the risk of a poor response but not that of insensitivity.

Conclusions: In future research, poor and insensitivity to bDMARDs should be assessed separately to fully elucidate the aetiology of, and risk factors for, bDMARD refractoriness.

Keywords: Rheumatoid arthritis, Tumour necrosis factor inhibitors, Insensitivity

\section{Background}

The development of biologic disease-modifying antirheumatic drugs (bDMARDs) has dramatically expanded the therapeutic options for patients with rheumatoid arthritis (RA) who are refractory to conventional synthetic DMARDs (csDMARDs). Global evidence indicates that when RA patients are refractory to csDMARDs, additive bDMARD treatment leads to clinical remission

\footnotetext{
* Correspondence: ochisae1024@gmail.com

'Department of Laboratory Medicine, Jikei University School of Medicine,

Nishi-shinbashi 3-25-8, Minatoku, Tokyo 105-8461, Japan

${ }^{2}$ First Department, University of Occupational and Environmental Health,

Iseigaoka 1-1, Yawatanishi-ku, Kitakyushu, Fukuoka 80708556, Japan

Full list of author information is available at the end of the article
}

in approximately $30-60 \%$ of the patients, a majority of whom also achieve structural remission [1]. Moreover, when treated with a bDMARD during the early stage of the disease, approximately half of RA patients can successfully remain in clinical remission without the need for bDMARDs with no radiological or functional damage progression of articular destruction [2, 3].

Even so, $20-30 \%$ of patients with RA remain refractory to treatment [4-6], and only half of patients treated with any single agent have a major benefit [7]. Refractory RA involves a variety of concepts [8]: thus far, the definition of this status is arbitrary, and data on the outcomes of these patients remain limited [9]. From a clinical viewpoint, the

(C) The Author(s). 2020 Open Access This article is distributed under the terms of the Creative Commons Attribution 4.0 International License (http://creativecommons.org/licenses/by/4.0/), which permits unrestricted use, distribution, and 
refractory status of RA can be roughly categorised into three groups: insensitivity, in which no improvement is observed from the start of treatment; secondary refractory, in which partial, but insufficient, improvement is evident; and false refractory, in which patients complain persistent pain though inflammation is absent [9].

Among these three conditions, identifying insensitivity to bDMARDs has significant clinical importance, because these patients experience no improvement in their symptoms by treatment, thus incurring unnecessary costs and toxicity [10]. Although a second bDMARD is recommended for both intrinsic and secondary refractory RA patients [11], total unresponsiveness might decrease the patient's motivation to try another treatment. In contrast, partial improvement of symptoms may increase the patient's adherence to bDMARDs, even if the effect is not sufficient. Therefore, identification of the factors causing insensitivity to bDMARDs is important for avoiding initial failure and improving patient adherence to subsequent therapies.

TNFis are the most frequently used and thus most wellstudied bDMARDs. Several factors potentially affecting the response to TNFis have been reported. It has been demonstrated that a high education level [12], low disability grade $[13,14]$ and usages of nonsteroidal anti-inflammatory drugs [13] and methotrexate (MTX) [15-17] are associated with a good response to TNFis, whereas a young age [18], obesity [19], smoking [20], high disease activity at the time of treatment [13], glucocorticoid usage [12, 18] and positivity for rheumatoid factor (RF) and anti-citrullinated protein (CCP) antibodies $[18,21]$ are associated with a poor response. However, these findings have not always been consistent across studies [8]. As a result, the choice of treatment usually depends on the route of administration, dose interval, chemical structure and cost rather than etiological factors. Considering the heterogeneity of the status of RA treatment refractoriness, this inconsistency may be due to including different refractory status types in one group. To achieve more personalised treatment, greater knowledge regarding categorisation of the refractory status is needed.

In this study, we retrospectively compared an insensitivity with a poor response to TNFis among bDMARD-naive RA patients with an inadequate response to csDMARDs (csDMARD-IR). The results may aid future assessments of the effectiveness of bDMARDs and improve optimisation of RA treatments.

\section{Methods}

FIRST registry

This was a retrospective cohort study using data from the FIRST registry, a cohort recruited by the University of Occupational and Environmental Health. The hospital and its affiliated hospitals accumulated data from RA patients treated with bDMARDs since the approval of the first DMARD in Japan in 2003 until May 2019. A total of 3389 patients were enrolled in this registry during this period, among whom TNFis (infliximab, etanercept, adalimumab, golimumab and certolizumab) were the most frequently used DMARDs $(n=2133)$ (Fig. 1).

\section{Study patients}

The clinical data of RA patients enrolled in the FIRST registry from August 2003 to May 2019 were collected. Patients with csDMARD-IR and bDMARD-naïve at the time of the treatment with a TNFi were included.

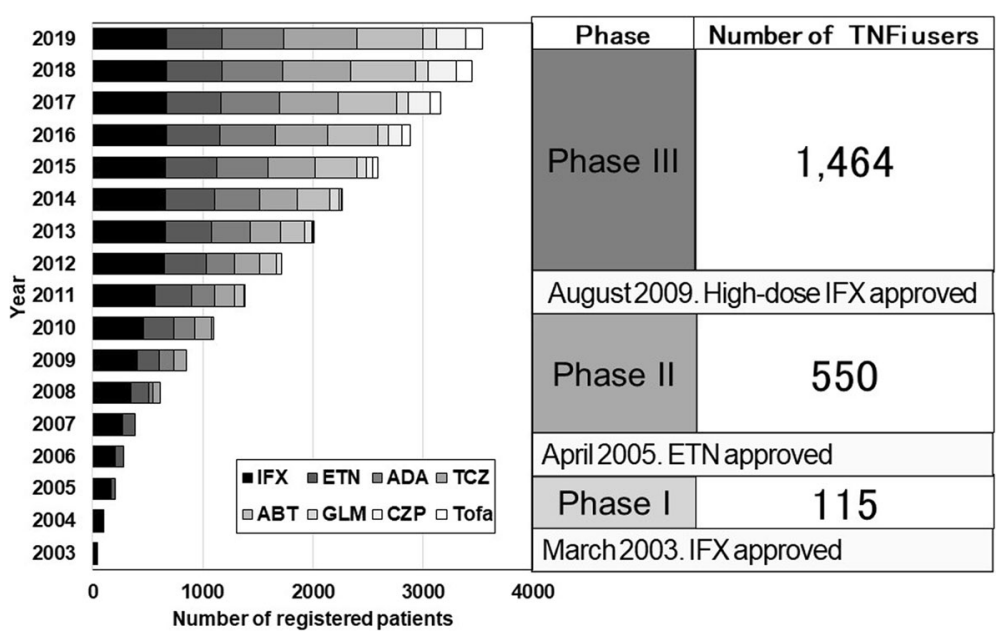

Fig. 1 Description of FIRST registry. Number of registered patients and distribution of biological disease-modifying anti-rheumatic drug (bDMARD) users by drug types in each year is shown. IFX, infliximab; ETN, etanercept; TCZ, tocilizumab; ADA, adalimumab; ABT, abatacept; GLM, golimumab; CZP, certolizumab; Tofa, tofacitinib 
Definitions of TNFi insensitivity and poor response to TNFis TNFi insensitivity was defined as either of the following conditions: (i) discontinuation of TNFi treatment within 22 weeks due to a lack of response or (ii) a significant increase in the disease activity score in 28 joints (DAS28)C-reactive protein (CRP) at week 22 compared with week 0 . Some previous studies assessed unresponsiveness at weeks 12-16 [9], but in this study, a proportion of the patients did not have data from that period, and thus week 22 was used as our assessment time point. For condition i above, a lack of response to TNFis was made by the RA specialists treating the patient. For condition ii, the DAS28 may fluctuate to some degree even if disease activity does not change. Therefore, an increase in the DAS28 of $>0.6$ was considered meaningful, based on the results of a previous study [22].

A poor response to TNFis was defined as moderate to high disease activity (DAS28-CRP of $>2.6$ at 22 weeks or DAS28-ESR of > 3.2). Other patients including those whose treatment was stopped were categorised in the control group.

\section{The phases of the FIRST registry}

The FIRST registry consists of three phases (Fig. 1). Phase I started from the time of approval in Japan of the first TNFi, infliximab, to the approval of the second $\mathrm{TNFi}$, etanercept, at which time phase II began. Therefore, in phase I, RA patients had only one TNFi option: infliximab. When high-dose $(10 \mathrm{mg} / \mathrm{kg})$ infliximab was approved, phase III began.

\section{Statistical analysis}

For continuous variables, the normality of the data was assessed using the Shapiro-Wilk test. For categorical variables, differences between groups were assessed using the chi-squared test. Associations of gender, age, disease duration, disease activity, RF, use of MTX, use of glucocorticoid, types of drugs and phases with the insensitivity and poor response groups were calculated using multiple logistic regression analysis.

The data available in this registry were age, disease duration, parameters used for calculating the DAS28 (number of tender joints, number of swollen joints, patient global health, CRP titre and erythrocyte sedimentation rate), doses of glucocorticoid and MTX, usage of other anti-rheumatic drugs, full health assessment questionnaire (HAQ), other laboratory data including levels of RF and anti-citrullinated protein antibodies, matrix metalloproteinase-3 (MMP-3), Krebs von den Lugen-6, bone alkaline phosphate and type I collagen cross-linked $\mathrm{N}$-telopeptide (NTx). As the numbers of swollen joints and tender joints and serum levels of inflammation markers are incorporated in the DAS28 calculation, these variables were not additionally included in the analysis. Other variables strongly interact with each other; for example, the HAQ may confound the DAS28 and levels of MMP-3 and bone alkaline phosphate, while NTx may confound glucocorticoid usage. In addition, due to the relatively small sample size of the TNFi insensitivity group, it seemed inappropriate to use regression model-fitting methods. Therefore, age, DAS28, use of glucocorticoids and MTX and RF positivity were selected as explanatory variables. To determine whether the variables interact with each other, logistic regression was also conducted with terms of interaction. $p$ value < 0.05 was considered statistically significant. All analyses were conducted using STATA/SE 13.1 (StataCorp LP, College Station, TX, USA).

\section{Results}

In total, 1620 patients with bDMARD-naïve and csDMARDIR RA were enrolled. Six patients were excluded because they received a higher dose of glucocorticoids ( $\geq 20 \mathrm{mg} /$ day) for the treatment of complications such as interstitial pneumonia and other autoimmune diseases. Another patient was also excluded because of missing data about the use of csDMARD. Among the remaining 1613 patients, 172 discontinued TNFi treatment within 22 weeks. Seventy-nine discontinued because of a poor treatment response and 92 discontinued from other reasons such as adverse effects or economic reasons (Fig. 2). Among the remaining 1442 patients, $15 \mathrm{had}$ an increase in the DAS28 of $>0.6$. As a result, 94 (6.2\%) were classified in the TNFi insensitivity group. Among the remaining, 604 showed DAS28-CRP $>2.6$ at week 22 and thus were classified in the poor response group. Those who showed low disease activity at week 22 and those who discontinued the treatment within 22 weeks for reasons

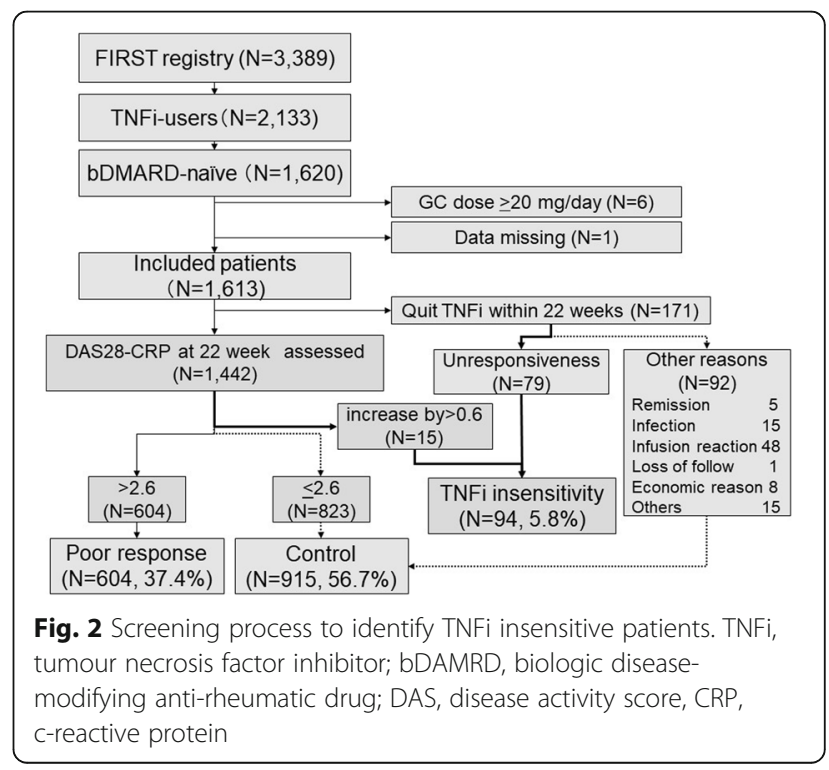


other than poor treatment response were allocated to the control group ( $N=915$, Fig. 2$)$.

\section{Background characteristics}

The background characteristics of the included patients are summarised in Table 1. The Shapiro-Wilk test revealed a non-normal distribution for all of the continuous variables listed in Table 1 . Therefore, these variables were converted into categorical variables for the statistical analyses. For RF and glucocorticoid, RF positivity and glucocorticoid usage were used instead of RF titre and glucocorticoid dose, respectively. Disease duration, MTX dose and number of treatment failures to previous csDMARDs were categorised.

Table 1 Patient background characteristics

\begin{tabular}{|c|c|c|c|}
\hline \multicolumn{2}{|c|}{ Background characteristics } & Mean & Median \\
\hline \multicolumn{2}{|l|}{ Age } & 59.2 & 61.0 \\
\hline \multicolumn{2}{|c|}{ Disease duration (months) } & 80.2 & 36.0 \\
\hline \multicolumn{2}{|c|}{ Number of swollen joints } & 8.2 & 7.0 \\
\hline \multicolumn{2}{|c|}{ Number of tender joints } & 9.4 & 8.0 \\
\hline \multicolumn{2}{|l|}{ DAS28ESR } & 5.7 & 5.7 \\
\hline \multicolumn{2}{|l|}{ DAS28CRP } & 5.0 & 4.9 \\
\hline \multicolumn{2}{|l|}{$\operatorname{ESR}(\mathrm{mm} / \mathrm{h})$} & 51.4 & 47.5 \\
\hline \multicolumn{2}{|l|}{ CRP $(\mathrm{mg} / \mathrm{dL})$} & 2.6 & 1.2 \\
\hline \multicolumn{2}{|l|}{$\mathrm{RF}(\mathrm{IU} / \mathrm{mL})$} & 164.9 & 64.4 \\
\hline \multicolumn{2}{|c|}{ MMP-3 (ng/mL) } & 272.5 & 152.0 \\
\hline \multicolumn{2}{|c|}{ Dose of MTX (mg/week) } & 9.7 & 10.0 \\
\hline \multicolumn{2}{|c|}{ Dose of GC (mg/day in prednisolone equivalent) } & 1.3 & 0.0 \\
\hline \multirow{2}{*}{\multicolumn{2}{|c|}{ Failure in csDMARDs }} & 2.0 & 2.0 \\
\hline & & Frequency & Percent \\
\hline \multirow[t]{2}{*}{ Gender } & Female & 1307 & 81.0 \\
\hline & Male & 307 & 19.0 \\
\hline \multirow[t]{3}{*}{ Entry phase } & 1 & 115 & 7.1 \\
\hline & $\|$ & 442 & 27.4 \\
\hline & III & 1056 & 65.5 \\
\hline \multirow[t]{5}{*}{ Biologics } & IFX & 643 & 39.8 \\
\hline & ETA & 372 & 23.1 \\
\hline & ADA & 404 & 25.0 \\
\hline & GLM & 25 & 1.6 \\
\hline & CZP & 170 & 10.5 \\
\hline \multicolumn{2}{|c|}{ Use of corticosteroid } & 446 & 27.6 \\
\hline \multicolumn{2}{|l|}{ Use of MTX } & 1436 & 89.0 \\
\hline \multicolumn{2}{|c|}{ Failure in $>2$ csDMARDs } & 903 & 56.0 \\
\hline \multicolumn{2}{|l|}{ RF positive* } & 1215 & 75.6 \\
\hline
\end{tabular}

${ }^{*} \mathrm{RF}>20 \mathrm{IU} / \mathrm{mL}$ was defined as positive

CRP C-reactive protein, ESR erythrocyte sedimentation rate, DAS28 disease activity score for 28 joints, $R F$ rheumatoid factor, MMP-3 matrix metalloproteinase, MTX methotrexate, csDMARDs conventional synthetic disease-modifying anti-rheumatic drugs
Comparisons of the background characteristics among the three groups are shown in Table 2. Each variable was compared between the groups using the chi-squared test, which revealed significant differences in disease duration, phases of the FIRST registry and TNFi drug type between the insensitive and poor response groups. Many factors showed significant differences between control and poor response groups, but only disease activity at week 0 showed significant difference between control and insensitivity groups.

\section{Differences in risk factors between the insensitivity and poor response groups}

Logistic regression analysis was conducted to identify factors associated with TNFi insensitivity or a poor response to TNFis, in comparison with the control group (Table 3). As the treatment option of high-dose infliximab became available in phase III of the FIRST registry, the phases were categorised as phase I + II versus phase III.

Sex, age, RF positivity, initial MTX dose and treatment failure to more than two csDMARDs were not associated with the risk of either TNFi insensitivity or a poor response to TNFis. Longer disease duration showed a lower risk of insensitivity. Interestingly, higher disease activity (DAS28-CRP > 4.1) before treatment was associated with a higher risk of a poor response, whereas this association was not observed in the TNFi insensitivity group. By contrast, the risk of a poor response was significantly decreased in phase III compared with phase I + II, suggesting that the higher dose of infliximab improved the responsiveness to TNFis. However, the risk of insensitivity did not change with the registry phase. Treatment with certolizumab showed a higher risk of insensitivity but a lower risk of a poor response. These discrepancies suggest that the two groups are intrinsically different.

We used DAS28-CRP as an indicator of disease activity because titres of ESR were not available for some patients. As DAS28-ESR is a commonly accepted indicator, we also conducted the same analysis with definition that DAS28-ESR $>3.2$ as refractory and $\leq 3.2$ as control (Table 4). In this case, DAS28-ESR $>3.2$ was a risk factor for both insensitivity and refractory status. On the other hand, there was more significant difference in the effect of gender, age category, disease duration, dose of MTX and phase. The effect of using certolizumab disappears.

Concomitant use of glucocorticoids seemed to be a common risk for both types of responsiveness. As glucocorticoid use can interact with other variables, logistic regression analysis was conducted including terms of interaction among all of the variables listed in Table 3; however, no significant interactions were observed (data not shown). Therefore, no interaction terms were incorporated in the final analysis. Also, if the glucocorticoid dose had been reduced during TNFi treatment, this 
Table 2 Comparison of patient background characteristics between a TNFi insensitivity group and a poor response group. For each variable, $p$ values of a simple comparison between the two groups using chi-squared test are shown

\begin{tabular}{|c|c|c|c|c|c|c|c|c|c|c|}
\hline \multirow[t]{2}{*}{ Category } & \multicolumn{2}{|c|}{ TNli insensitivity } & \multicolumn{3}{|c|}{ Refractory } & \multicolumn{2}{|l|}{ Control } & \multicolumn{3}{|c|}{$p$ value ${ }^{*}$} \\
\hline & & $\bar{N}$ & $\%$ & $N$ & $\%$ & $\bar{N}$ & $\%$ & $\overline{\mathrm{P} 1}$ & P2 & P3 \\
\hline \multirow[t]{2}{*}{ Gender } & Female & 75 & 79.8 & 501 & 82.9 & 731 & 79.9 & 0.83 & 0.14 & 0.34 \\
\hline & Male & 19 & 20.2 & 103 & 17.1 & 184 & 20.1 & & & \\
\hline \multirow[t]{4}{*}{ Age group } & $\leqq 50$ & 23 & 24.5 & 129 & 21.4 & 228 & 24.9 & 0.62 & 0.41 & 0.48 \\
\hline & $51-60$ & 26 & 27.7 & 149 & 24.7 & 205 & 22.4 & & & \\
\hline & $61-70$ & 19 & 20.2 & 165 & 27.3 & 246 & 26.9 & & & \\
\hline & 71 & 26 & 27.7 & 161 & 26.7 & 236 & 25.8 & & & \\
\hline \multirow[t]{4}{*}{ Disease duration (year) } & $<0.5$ & 22 & 23.4 & 75 & 12.4 & 165 & 18.0 & 0.45 & $<0.01^{\dagger}$ & $0.01^{\dagger}$ \\
\hline & $0.5-2$ & 31 & 33.0 & 163 & 27.0 & 284 & 31.0 & & & \\
\hline & $2-5$ & 17 & 18.1 & 117 & 19.4 & 159 & 17.4 & & & \\
\hline & $\geq 5$ & 24 & 25.5 & 247 & 40.9 & 306 & 33.4 & & & \\
\hline \multirow[t]{3}{*}{ DAS28-CRP at week 0} & $<3.2$ & 3 & 3.2 & 6 & 1.0 & 43 & 4.7 & $<0.01^{\dagger}$ & $<0.01^{\dagger}$ & 0.18 \\
\hline & $3.2-5.1$ & 12 & 12.8 & 94 & 15.6 & 259 & 28.3 & & & \\
\hline & $>5.1$ & 79 & 84.0 & 502 & 83.1 & 613 & 67.0 & & & \\
\hline \multirow[t]{2}{*}{ RF positivity** } & Negative & 25 & 26.6 & 127 & 21.0 & 240 & 26.2 & 0.95 & $0.02^{+}$ & 0.24 \\
\hline & Positive & 69 & 73.4 & 473 & 78.3 & 673 & 73.6 & & & \\
\hline \multirow[t]{2}{*}{ Use of GC } & No & 66 & 70.2 & 393 & 65.1 & 708 & 77.4 & 0.13 & $<0.01^{\dagger}$ & 0.30 \\
\hline & Yes & 28 & 29.8 & 211 & 34.9 & 207 & 22.6 & & & \\
\hline \multirow[t]{5}{*}{ Dose of MTX (mg/week) } & 0 & 13 & 13.8 & 81 & 13.4 & 83 & 9.1 & 0.22 & $<0.01^{\dagger}$ & 0.47 \\
\hline & $1-6$ & 10 & 10.6 & 74 & 12.3 & 79 & 8.6 & & & \\
\hline & $7-9$ & 22 & 23.4 & 189 & 31.3 & 218 & 23.8 & & & \\
\hline & $10-15$ & 32 & 34.0 & 176 & 29.1 & 294 & 32.1 & & & \\
\hline & $>15$ & 17 & 18.1 & 84 & 13.9 & 241 & 26.3 & & & \\
\hline \multirow[t]{2}{*}{ Failure in $>2$ csDMARDs } & No & 44 & 46.8 & 301 & 49.8 & 365 & 39.9 & 0.16 & $<0.01^{\dagger}$ & 0.66 \\
\hline & Yes & 50 & 53.2 & 303 & 50.2 & 550 & 60.1 & & & \\
\hline \multirow[t]{3}{*}{ Entry phase } & I & 29 & 30.9 & 287 & 47.5 & 327 & 35.7 & 0.11 & $<0.01^{\dagger}$ & $<0.01^{\dagger}$ \\
\hline & $\|$ & 24 & 25.5 & 169 & 28.0 & 179 & 19.6 & & & \\
\hline & III & 22 & 23.4 & 95 & 15.7 & 287 & 31.4 & & & \\
\hline \multirow[t]{5}{*}{ Drug type } & IFX & 2 & 2.1 & 11 & 1.8 & 12 & 1.3 & 0.77 & $<0.01^{\dagger}$ & $<0.01^{\dagger}$ \\
\hline & ETN & 17 & 18.1 & 42 & 7.0 & 110 & 12.0 & & & \\
\hline & $\mathrm{ADA}$ & 5 & 5.3 & 55 & 9.1 & 55 & 6.0 & & & \\
\hline & GLM & 22 & 23.4 & 234 & 38.7 & 186 & 20.3 & & & \\
\hline & CZP & 67 & 71.3 & 315 & 52.2 & 674 & 73.7 & & & \\
\hline
\end{tabular}

*P1, comparison between control and insensitivity; P2, comparison between control and refractory; P3, comparison between insensitivity and refractory ${ }^{* *} \mathrm{RF}>20 \mathrm{IU} / \mathrm{mL}$ was defined as positive

${ }^{\dagger} p<0.05$

DAS28 disease activity score for 28 joints, CRP c-reactive protein, MTX methotrexate, IFX infliximab, ETA etanercept, ADA adalimumab, GLM golimumab, CZP certolizumab, cSDMARDs conventional synthetic disease-modifying anti-rheumatic drugs

could have decreased the erythrocyte sedimentation rate and CRP level and thereby increased the DAS28. Therefore, we calculated the mean difference in the glucocorticoid dose between week 0 and week 22 among the patients taking glucocorticoids (Suppl. Table 1). The mean reductions in the glucocorticoid dose were 0.49 $\mathrm{mg} /$ day in the insensitivity group, $0.55 \mathrm{mg}$ /day in the poor response group and $0.35 \mathrm{mg} /$ day in the control group. The glucocorticoid dose was reduced in $8.5 \%$ of the TNFi insensitive patients, $11.4 \%$ of the poor response patients and $11.8 \%$ of the control patients. There was no statistical difference among the three groups.

\section{Discussion}

With advances in the treatment of RA, optimising the outcomes of difficult-to-treat patients has become increasingly 
Table 3 Multivariable logistic regression analyses for TNFi-insensitivity and poor response to a TNFi

\begin{tabular}{|c|c|c|c|c|c|c|c|}
\hline \multirow[t]{2}{*}{ Category } & \multicolumn{3}{|c|}{ TNFi insensitivity } & \multicolumn{2}{|r|}{ Poor response } & \multirow[b]{2}{*}{$95 \% \mathrm{Cl}$} & \multirow[b]{2}{*}{$p$} \\
\hline & & $\overline{\mathrm{OR}}$ & $95 \% \mathrm{Cl}$ & $p$ & $\overline{\mathrm{OR}}$ & & \\
\hline \multirow[t]{2}{*}{ Gender } & Female & 1 (reference) & & & 1 (reference) & & \\
\hline & Male & 0.99 & $0.57-1.71$ & 0.97 & 0.77 & $0.58-1.03$ & 0.08 \\
\hline \multirow[t]{4}{*}{ Age category } & $\leqq 50$ & 1 (reference) & & & 1 (reference) & & \\
\hline & $51-60$ & 1.27 & $0.69-2.34$ & 0.44 & 1.35 & $0.97-1.86$ & 0.07 \\
\hline & $61-70$ & 0.68 & $0.35-1.32$ & 0.25 & 1.14 & $0.82-1.58$ & 0.43 \\
\hline & $\geqq 71$ & 0.79 & $0.40-1.55$ & 0.49 & 1.04 & $0.74-1.47$ & 0.83 \\
\hline \multirow[t]{4}{*}{ Duration (year) } & $<0.5$ & 1 (reference) & & & 1 (reference) & & \\
\hline & $0.5-2$ & 0.87 & $0.47-1.59$ & 0.65 & 1.24 & $0.87-1.76$ & 0.24 \\
\hline & $2-5$ & 0.75 & $0.37-1.53$ & 0.43 & 1.27 & $0.86-1.89$ & 0.23 \\
\hline & $\geq 5$ & 0.51 & $0.26-1.01$ & $0.05^{\dagger}$ & 1.16 & $0.81-1.66$ & 0.43 \\
\hline \multirow[t]{3}{*}{ DAS28-CRP } & $<2.6$ & 1 (reference) & & & 1 (reference) & & \\
\hline & $2.6-4.1$ & 0.52 & $0.10-2.61$ & 0.42 & 3.71 & $0.83-16.53$ & 0.09 \\
\hline & $>4.1$ & 1.46 & $0.31-6.79$ & 0.63 & 6.93 & $1.57-30.48$ & $0.01^{\dagger}$ \\
\hline RF positivity* & & 0.99 & $0.60-1.63$ & 0.97 & 1.08 & $0.83-1.41$ & 0.58 \\
\hline Concomitant use of GC & & 1.71 & $1.02-2.87$ & $0.04^{+}$ & 1.29 & $1.00-1.67$ & $0.05^{+}$ \\
\hline \multirow[t]{5}{*}{ Dose of MTX (mg/week) } & 0 & 1 (reference) & & & 1 (reference) & & \\
\hline & $1-6$ & 1.22 & $0.45-3.30$ & 0.70 & 0.86 & $0.52-1.45$ & 0.58 \\
\hline & $7-9$ & 0.88 & $0.37-2.06$ & 0.76 & 1.04 & $0.67-1.60$ & 0.87 \\
\hline & $10-15$ & 0.87 & $0.38-1.97$ & 0.73 & 0.93 & $0.60-1.43$ & 0.73 \\
\hline & $>15$ & 0.60 & $0.24-1.46$ & 0.26 & 0.69 & $0.43-1.11$ & 0.13 \\
\hline Failure in $>2$ csDMARDs & & 0.67 & $0.42-1.07$ & 0.09 & 0.86 & $0.68-1.08$ & 0.20 \\
\hline \multirow[t]{5}{*}{ Biologics } & $\mathrm{IFX}$ & 1 (reference) & & & 1 (reference) & & \\
\hline & ETA & 1.63 & $0.77-3.44$ & 0.20 & 1.19 & $0.84-1.69$ & 0.33 \\
\hline & $\mathrm{ADA}$ & 1.03 & $0.53-2.00$ & 0.94 & 0.59 & $0.43-0.83$ & $<0.01^{\dagger}$ \\
\hline & GLM & 2.19 & $0.42-11.40$ & 0.35 & 1.95 & $0.80-4.77$ & 0.14 \\
\hline & CZP & 2.64 & $1.32-5.28$ & $0.01^{\dagger}$ & 0.64 & $0.41-0.98$ & $0.04^{+}$ \\
\hline \multirow[t]{2}{*}{ Phase } & $I+\|$ & 1 (reference) & & & 1 (reference) & & \\
\hline & III & 1.30 & $0.71-2.38$ & 0.39 & 0.65 & $0.49-0.88$ & $0.01^{\dagger}$ \\
\hline
\end{tabular}

DAS28 disease activity score for 28 joints, CRP c-reactive protein, MTX methotrexate, $G C$ glucocorticoid, $O R$ odds ratio, $C l$ confidence interval

${ }^{*} \mathrm{RF}>20 \mathrm{IU} / \mathrm{mL}$ was defined as positive

${ }^{\dagger} p<0.05$

important in clinical practice $[8,9]$. Although the global consensus is that there is a wide variation in difficult-totreat statuses, few studies have stratified the patients by response patterns. This cohort study is the first to show an epidemiological difference between insensitivity and a poor response to additive treatment with TNFis in patients with CSDMARD-IR and bDMARD-naive RA. The differences in risk factors detected between these two groups strongly suggest that TNFi insensitivity is not simply a more severe form of a poor response.

Interestingly, the option of infliximab dose escalation in phase III seemed to reduce the risk of a poor treatment response (Table 3 and Supplementary table 1), but no such association was observed in the insensitivity group.
These results may explain the current controversial results on the effectiveness of dose escalation of infliximab for RA patients [23-26]; if patients with TNFi insensitivity are etiologically different from those with a poor response to $\mathrm{TNFi}$, combining these patients into one outcome group as a 'refractory group' may mask the net effect of dose escalation among patients with a poor response. Therefore, if a patient responds to TNFi treatment to some extent, it is worth trying to increase the dose, but if disease activity worsens during treatment, increasing the dose is unlikely to have an effect. Further research is needed on whether patients with insensitivity to a TNFi also have a higher risk of insensitivity to other TNFis, to help select the second bDMARD for these patients. 
Table 4 Multivariable logistic regression analyses for TNFi-insensitivity and poor response to a TNFi using DAS28-ESR

\begin{tabular}{|c|c|c|c|c|c|c|c|c|}
\hline \multirow[t]{2}{*}{ Category } & \multicolumn{4}{|c|}{ TNFi insensitivity $(N=91)$} & \multicolumn{4}{|c|}{ Insufficient response $(N=453)$} \\
\hline & & $\overline{\mathrm{OR}}$ & $95 \% \mathrm{Cl}$ & & $p$ & $\overline{\mathrm{OR}}$ & $95 \% \mathrm{Cl}$ & $p$ \\
\hline \multirow[t]{2}{*}{ Gender } & \multicolumn{2}{|c|}{ Female 1 (reference) } & \multicolumn{6}{|c|}{1 (reference) } \\
\hline & Male & 0.72 & $0.40-1.29$ & & 0.27 & 0.49 & $0.35-0.69$ & $<0.01^{\dagger}$ \\
\hline \multirow[t]{4}{*}{ Age category } & $\leqq 50$ & 1 (reference) & \multicolumn{6}{|c|}{1 (reference) } \\
\hline & $51-60$ & 1.26 & $0.69-2.32$ & & 0.45 & 1.78 & $1.22-2.60$ & $<0.01^{\dagger}$ \\
\hline & $61-70$ & 0.72 & $0.36-1.42$ & & 0.34 & 1.72 & $1.18-2.51$ & $0.01^{\dagger}$ \\
\hline & $\geqq 71$ & 0.99 & $0.51-1.90$ & & 0.97 & 1.91 & $1.30-2.81$ & $<0.01^{\dagger}$ \\
\hline \multirow[t]{4}{*}{ Duration (year) } & $<0.5$ & 1 (reference) & \multicolumn{6}{|c|}{1 (reference) } \\
\hline & $0.5-2$ & 0.37 & $0.14-0.96$ & & $0.04^{\dagger}$ & 0.94 & $0.44-2.01$ & 0.87 \\
\hline & $2-5$ & 0.29 & $0.10-0.84$ & & $0.02^{\dagger}$ & 0.87 & $0.40-1.91$ & 0.73 \\
\hline & $\geq 5$ & 0.14 & 0.05 & 0.41 & $<0.01^{\dagger}$ & 0.90 & $0.43-1.90$ & 0.79 \\
\hline \multirow[t]{2}{*}{ DAS28-ESR at week 0} & $\leqq 3.2$ & 1 (reference) & \multicolumn{6}{|c|}{1 (reference) } \\
\hline & $>3.2$ & 2.62 & $1.54-4.47$ & & $<0.01^{\dagger}$ & 2.53 & $1.91-3.36$ & $<0.01^{\dagger}$ \\
\hline RF positivity* & & 0.99 & $0.59-1.65$ & & 0.97 & 1.28 & $0.95-1.73$ & 0.11 \\
\hline Concomitant use of GC & & 1.49 & 0.88 & 2.51 & 0.14 & 1.34 & $1.01-1.79$ & $0.05^{\dagger}$ \\
\hline \multirow[t]{5}{*}{ Dose of MTX (mg/week) } & 0 & 1 (reference) & \multicolumn{6}{|c|}{1 (reference) } \\
\hline & $1-6$ & 1.02 & $0.38-2.72$ & & 0.97 & 0.71 & $0.41-1.22$ & 0.22 \\
\hline & $7-9$ & 0.69 & $0.31-1.57$ & & 0.38 & 0.73 & $0.47-1.15$ & 0.17 \\
\hline & $10-15$ & 0.73 & $0.34-1.56$ & & 0.41 & 0.63 & $0.40-0.97$ & $0.04^{\dagger}$ \\
\hline & $>15$ & 0.48 & $0.20-1.14$ & & 0.10 & 0.56 & $0.34-0.91$ & $0.02^{+}$ \\
\hline Failure in $>2$ csDMARDs & & 1.64 & $0.67-4.04$ & & 0.28 & 1.09 & $0.74-1.63$ & 0.66 \\
\hline \multirow[t]{5}{*}{ Biologics } & $\mathrm{IFX}$ & 1 (reference) & \multicolumn{6}{|c|}{1 (reference) } \\
\hline & ETA & 1.35 & $0.40-4.49$ & & 0.63 & 1.17 & $0.66-2.09$ & 0.59 \\
\hline & ADA & 1.51 & $0.66-3.44$ & & 0.33 & 0.81 & $0.55-1.20$ & 0.29 \\
\hline & GLM & 3.71 & $0.67-20.69$ & & 0.14 & 1.55 & $0.55-4.32$ & 0.41 \\
\hline & CZP & 1.13 & $0.22-5.66$ & & 0.89 & 0.46 & $0.19-1.12$ & 0.09 \\
\hline \multirow[t]{2}{*}{ Phase } & $1+\|$ & 1 (reference) & \multicolumn{6}{|c|}{1 (reference) } \\
\hline & III & 1.49 & $0.82-2.70$ & & 0.19 & 0.71 & $0.52-0.97$ & $0.03^{+}$ \\
\hline
\end{tabular}

The risk of insensitivity or a poor response also appeared to vary by drug type. Especially, certolizumab showed a higher risk of insensitivity but a lower risk of a poor response, compared with infliximab, although the difference in risk between the two drugs could not be compared due to the small sample size. As this study included only bDMARD-naïve patients, further research is needed to determine the difference in the effectiveness of bDMARDs in different clinical settings.

Our study also suggested that concomitant use of glucocorticoids may modify the responsiveness of bDMARDnaïve patients to TNFis. This is consistent with previous studies that showed glucocorticoids to be a negative predictor of the clinical response to bDMARDs, including TNFis [12, 18] and tocilizumab [27, 28]. Several possible reasons may explain this negative correlation. First, as glucocorticoids mask disease activity, concomitant use of these agents may indicate high disease activity or the presence of refractory disease prior to administration of a TNFi. However, whether this explains the refractory status and/or exacerbation of symptoms during treatment remains uncertain. Second, previous reports suggested that the effect of TNFis is related to monocytes $[29,30]$. For example, a TNFi was reported to increase the secretion of the soluble TNF receptor, a natural inhibitor of TNF, and production of interleukin 10 by monocytes [31]. As glucocorticoids reduce the number of peripheral monocytes, the use of glucocorticoids with a TNFi may decrease this monocyte-dependent anti-rheumatic effect of TNFis. Third, changes in the profiles of hypothalamic-pituitary-adrenal axis hormones may have affected the responsiveness to TNFi. Previous studies have shown that 
endogenous levels of hormones in this axis are closely related to the outcome of TNFi treatment [16], and an increased adrenocorticotropic hormone (ACTH) level, $\mathrm{ACTH} /$ cortisol ratio and endogenous cortisol level are predictors of a good outcome [32]. Therefore, it is possible that suppression of ACTH by glucocorticoids may affect the TNFi refractory status.

Even so, transient treatment with low-dose glucocorticoids is reported to be beneficial for preventing bone and joint destruction [33-37] and prolonging life expectancy in patients with RA [38], which makes low-dose glucocorticoids a candidate initial treatment for RA [11]. Therefore, glucocorticoids should not be avoided merely because they may influence the responsiveness to TNFis. Instead, when glucocorticoid-naive patients are refractory to csDMARDs, the introduction of TNFis before glucocorticoids might be recommended.

This study was limited by its inherently retrospective nature. In particular, the judgement of 'a lack of response' was left up to the head physician, which might have resulted in heterogeneity among the patient group with no response to TNFis. Ideally, the judgement of a lack of response should be made by objective data such as the DAS28 at the time of deciding whether to discontinue treatment. However, data at the time of making this decision was available for a limited number of patients only, and we relied on the physician's judgement for determining a lack of response.

Another limitation is that this analysis could not completely eliminate the effect of background heterogeneity. For example, usage of glucocorticoids may indicate the presence of chronic renal failure, for which administration of high-dose MTX is difficult. In addition to these limitations, there is no global standard for insensitivity to TNFis, and the definition used in this study may need to be validated in future clinical studies. Finally, this research did not elucidate the mechanisms of insensitivity. Further research is needed, including similar studies using other bDMARDs, as well as analyses of the immune profiles of the patients.

\section{Conclusions}

This is the first study to show epidemiological differences between patients with TNFi insensitivity and those with a poor response to TNFis among csDMARDIR and bDMARD-naïve patients with RA. Differences in the risk factors between the two groups strongly suggest that the two statuses are different entities, although immunological and serological studies are required to elucidate the aetiology. Further research is required including a similar study involving other bDMARDs to increase understanding of the treatment options to avoid incorrect targeting of the disease.

\section{Supplementary information}

Supplementary information accompanies this paper at https://doi.org/10. 1186/s13075-020-2122-5.

Additional file 1: Table 1. Dose reduction of glucocorticoid at 22 weeks. Only those who were treated with glucocorticoid are included.

\begin{abstract}
Abbreviations
bDMARD: Biologic disease-modifying anti-rheumatic drug; CCP: Citrullinated protein; CRP: C-reactive protein; CsDMARD: Conventional synthetic DMARD; CSDMARDs-IR: Inadequate response to csDMARDs; DAS28: Disease activity score in 28 joints; HAQ: Health assessment questionnaire; MMP-3: Matrix metalloproteinase-3; MTX: Methotrexate; NTx: Type I collagen cross-linked Ntelopeptide; RA: Rheumatoid arthritis; RF: Rheumatoid factor; TNFi: Tumour necrosis factor inhibitor
\end{abstract}

\section{Acknowledgements}

We appreciate all the staff members of the First Department, University of Occupational and Environmental Health, and its affiliated hospitals for collecting patients' data and obtaining informed consent.

\section{Authors' contributions}

KS and YS designated the FIRST registry system. SO analysed and interpreted the patient data regarding the effectiveness of TNF inhibitors. SK, FM, KS and YT scrutinised and interpreted the results of the analysis. FM designated the layout of tables. SO and SK were major contributors in writing the manuscript, performed the histological examination of the kidney and was a major contributor in writing the manuscript. All authors read and approved the final manuscript.

\section{Funding}

Y. T. has received consulting fees, speaking fees and/or honoraria from Abbvie, Chugai, Daiichi-Sankyo, Bristol-Myers, Mitsubishi-Tanabe, Astellas, Takeda, Pfizer, Teijin, Asahi-Kasei, YL Biologics, Sanofi, Janssen, Eli Lilly and GlaxoSmithKline and has received research grants from Mitsubishi-Tanabe, Takeda, Daiichi-Sankyo, Chugai, Bristol-Myers, MSD, Astellas, Abbvie and Eisai.

F.M. has received research funding and/or speaking fees from AbbVie, Asahi Kasei Pharma, Astellas Pharma, Bristol-Myers Squibb, Chugai Pharmaceutical, Daiichi Sankyo Company, Eisai, Eli Lilly and Company, Janssen Pharmaceutical, Japan Blood Products Organization, Mitsubishi Tanabe Pharma, Novartis Pharma Japan, Ono Pharmaceutical, Pfizer, Sanofi, Takeda Pharmaceutical Company, Teijin and UCB Japan.

\section{Availability of data and materials}

The datasets generated and/or analysed during the current study are available in the FIRST registry of the University of Occupational and Environmental Health. The datasets are not publicly available due to our privacy policy but are available from the corresponding author on reasonable request.

\section{Ethics approval and consent to participate}

This study complies with the Declaration of Helsinki and the institutional review board of the University of Occupation and Environmental Health approved the study. Informed consent was obtained from all participants of the FIRST study.

\section{Consent for publication}

Not applicable

\section{Competing interests}

The authors declare that they have no competing interests.

\section{Author details}

${ }^{1}$ Department of Laboratory Medicine, Jikei University School of Medicine, Nishi-shinbashi 3-25-8, Minatoku, Tokyo 105-8461, Japan. ²First Department, University of Occupational and Environmental Health, Iseigaoka 1-1, Yawatanishi-ku, Kitakyushu, Fukuoka 80708556, Japan. ${ }^{3}$ Department of Rheumatology, Graduate School of Medical and Dental Sciences, Tokyo Medical and Dental University (TMDU), Yushima 1-5-45, Bunkyo-ku, Tokyo 113-8510, Japan. ${ }^{4}$ Center for Regional Cooperation, Iwaki Meisei University, Chuodai lino 5-5-1, Iwaki, Fukushima 970-8551, Japan. 


\section{Received: 26 September 2019 Accepted: 6 February 2020} Published online: 04 March 2020

\section{References}

1. Tanaka Y. Current concepts in the management of rheumatoid arthritis. Korean J Intern Med. 2016:31:210-8.

2. Tanaka Y. Next stage of RA treatment: is TNF inhibitor-free remission a possible treatment goal? Ann Rheum Dis. 2013;72(Suppl 2):ii124-7.

3. Tanaka Y. Intensive treatment and treatment holiday of TNF-inhibitors in rheumatoid arthritis. Curr Opin Rheumatol. 2012;24:319-26.

4. Lipsky PE, van der Heijde DM, St Clair EW, Furst DE, Breedveld FC, Kalden JR, et al. Infliximab and methotrexate in the treatment of rheumatoid arthritis. Anti-tumor necrosis factor trial in rheumatoid arthritis with concomitant therapy study group. N Engl J Med. 2000;343(22):1594-602.

5. Weinblatt ME, Kremer JM, Bankhurst AD, Bulpitt KJ, Fleischmann RM, Fox RI, et al. A trial of etanercept, a recombinant tumor necrosis factor receptor:FC fusion protein, in patients with rheumatoid arthritis receiving methotrexate. N Engl J Med. 1999;340(4):253-9.

6. Weinblatt ME, Keystone EC, Furst DE, Moreland LW, Weisman MH, Birbara CA, et al. Adalimumab, a fully human anti-tumor necrosis factor alpha monoclonal antibody, for the treatment of rheumatoid arthritis in patients taking concomitant methotrexate: the ARMADA trial. Arthritis Rheum. 2003; 48(1):35-45

7. Choy EH, Kavanaugh AF, Jones SA. The problem of choice: current biologic agents and future prospects in RA. Nat Rev Rheumatol. 2013;9(3):154-63.

8. Roodenrijs NMT, de Hair MJH, van der Goes MC, Jacobs JWG, Welsing PMJ, van der Heijde D, et al. Characteristics of difficult-to-treat rheumatoid arthritis: results of an international survey. Ann Rheum Dis. 2018;77(12): 1705-9

9. Buch MH. Defining refractory rheumatoid arthritis. Ann Rheum Dis. 2018; 77(7):966-9.

10. Romao VC, Vital EM, Fonseca JE, Buch MH. Right drug, right patient, right time: aspiration or future promise for biologics in rheumatoid arthritis? Arthritis Res Ther. 2017;19(1):239.

11. Smolen JS, Landewe R, Breedveld FC, Buch M, Burmester G, Dougados M, et al. EULAR recommendations for the management of rheumatoid arthritis with synthetic and biological disease-modifying antirheumatic drugs: 2013 update. Ann Rheum Dis. 2014;73(3):492-509.

12. Canhao H, Rodrigues AM, Mourao AF, Martins F, Santos MJ, Canas-Silva J, et al. Comparative effectiveness and predictors of response to tumour necrosis factor inhibitor therapies in rheumatoid arthritis. Rheumatology (Oxford). 2012;51(11):2020-6.

13. Hyrich KL, Watson KD, Silman AJ, Symmons DP, British Society for Rheumatology Biologics R. Predictors of response to anti-TNF-alpha therapy among patients with rheumatoid arthritis: results from the British Society for Rheumatology Biologics Register. Rheumatology (Oxford). 2006;45(12):1558-65.

14. Aletaha D, Funovits J, Keystone EC, Smolen JS. Disease activity early in the course of treatment predicts response to therapy after one year in rheumatoid arthritis patients. Arthritis Rheum. 2007;56(10):3226-35.

15. Breedveld FC, Weisman MH, Kavanaugh AF, Cohen SB, Pavelka K, van Vollenhoven $\mathrm{R}$, et al. The PREMIER study: a multicenter, randomized, doubleblind clinical trial of combination therapy with adalimumab plus methotrexate versus methotrexate alone or adalimumab alone in patients with early, aggressive rheumatoid arthritis who had not had previous methotrexate treatment. Arthritis Rheum. 2006;54(1):26-37.

16. Smolen JS, Van Der Heijde DM, St Clair EW, Emery P, Bathon JM, Keystone E, et al. Predictors of joint damage in patients with early rheumatoid arthritis treated with high-dose methotrexate with or without concomitant infliximab: results from the ASPIRE trial. Arthritis Rheum. 2006;54(3):702-10.

17. Soubrier M, Puechal X, Sibilia J, Mariette X, Meyer O, Combe B, et al. Evaluation of two strategies (initial methotrexate monotherapy vs its combination with adalimumab) in management of early active rheumatoid arthritis: data from the GUEPARD trial. Rheumatology (Oxford). 2009;48(11):1429-34

18. Hetland ML, Christensen IJ, Tarp U, Dreyer L, Hansen A, Hansen IT, et al. Direct comparison of treatment responses, remission rates, and drug adherence in patients with rheumatoid arthritis treated with adalimumab, etanercept, or infliximab: results from eight years of surveillance of clinical practice in the nationwide Danish DANBIO registry. Arthritis Rheum. 2010; 62(1):22-32
19. Gremese E, Carletto A, Padovan M, Atzeni F, Raffeiner B, Giardina AR, et al. Obesity and reduction of the response rate to anti-tumor necrosis factor alpha in rheumatoid arthritis: an approach to a personalized medicine. Arthritis Care Res (Hoboken). 2013;65(1):94-100.

20. Saevarsdottir S, Wedren S, Seddighzadeh M, Bengtsson C, Wesley A, Lindblad S, et al. Patients with early rheumatoid arthritis who smoke are less likely to respond to treatment with methotrexate and tumor necrosis factor inhibitors: observations from the Epidemiological Investigation of Rheumatoid Arthritis and the Swedish Rheumatology Register cohorts. Arthritis Rheum. 2011;63(1):26-36.

21. Vastesaeger N, Xu S, Aletaha D, St Clair EW, Smolen JS. A pilot risk model for the prediction of rapid radiographic progression in rheumatoid arthritis. Rheumatology (Oxford). 2009;48(9):1114-21.

22. Den Broeder AA, Creemers MC, van Gestel AM, van Riel PL. Dose titration using the Disease Activity Score (DAS28) in rheumatoid arthritis patients treated with anti-TNF-alpha. Rheumatology (Oxford). 2002;41(6):638-42.

23. Pavelka K, Jarosova K, Suchy D, Senolt L, Chroust K, Dusek L, et al. Increasing the infliximab dose in rheumatoid arthritis patients: a randomised, double blind study failed to confirm its efficacy. Ann Rheum Dis. 2009;68(8):1285-9.

24. Rahman MU, Strusberg I, Geusens P, Berman A, Yocum D, Baker D, et al. Double-blinded infliximab dose escalation in patients with rheumatoid arthritis. Ann Rheum Dis. 2007;66(9):1233-8.

25. Sidiropoulos P, Bertsias G, Kritikos HD, Kouroumali $H$, Voudouris K, Boumpas DT. Infliximab treatment for rheumatoid arthritis, with dose titration based on the Disease Activity Score: dose adjustments are common but not always sufficient to assure sustained benefit. Ann Rheum Dis. 2004;63(2):144-8.

26. Takeuchi T, Miyasaka N, Tatsuki Y, Yano T, Yoshinari T, Abe T, et al. Baseline tumour necrosis factor alpha levels predict the necessity for dose escalation of infliximab therapy in patients with rheumatoid arthritis. Ann Rheum Dis. 2011;70(7):1208-15.

27. Yamanaka H, Tanaka Y, Sekiguchi N, Inoue E, Saito K, Kameda H, et al. Retrospective clinical study on the notable efficacy and related factors of infliximab therapy in a rheumatoid arthritis management group in Japan (RECONFIRM). Mod Rheumatol. 2007;17(1):28-32.

28. Takeuchi T, Tanaka Y, Amano K, Hoshi D, Nawata M, Nagasawa H, et al. Clinical, radiographic and functional effectiveness of tocilizumab for rheumatoid arthritis patients--REACTION 52-week study. Rheumatology (Oxford). 2011;50(10):1908-15.

29. Nazareth N, Magro F, Silva J, Duro M, Gracio D, Coelho R, et al. Infliximab therapy increases the frequency of circulating CD16(+) monocytes and modifies macrophage cytokine response to bacterial infection. Clin Exp Immunol. 2014;177(3):703-11.

30. Gibellini L, De Biasi S, Bianchini E, Bartolomeo R, Fabiano A, Manfredini M, et al. Anti-TNF-alpha drugs differently affect the TNFalpha-sTNFR system and monocyte subsets in patients with psoriasis. PLoS One. 2016;11(12): e0167757.

31. Ebert EC. Infliximab and the TNF-alpha system. Am J Physiol Gastrointest Liver Physiol. 2009;296(3):G612-20.

32. Straub RH, Pongratz G, Cutolo M, Wijbrandts CA, Baeten D, Fleck M, et al. Increased cortisol relative to adrenocorticotropic hormone predicts improvement during anti-tumor necrosis factor therapy in rheumatoid arthritis. Arthritis Rheum. 2008;58(4):976-84.

33. Boers M, Verhoeven AC, Markusse HM, van de Laar MA, Westhovens $R$, van Denderen JC, et al. Randomised comparison of combined step-down prednisolone, methotrexate and sulphasalazine with sulphasalazine alone in early rheumatoid arthritis. Lancet. 1997;350(9074):309-18.

34. Kirwan JR. The effect of glucocorticoids on joint destruction in rheumatoid arthritis. The arthritis and rheumatism council low-dose glucocorticoid study group. N Engl J Med. 1995;333(3):142-6.

35. Landewe RB, Boers M, Verhoeven AC, Westhovens R, van de Laar MA, Markusse HM, et al. COBRA combination therapy in patients with early rheumatoid arthritis: long-term structural benefits of a brief intervention. Arthritis Rheum. 2002;46(2):347-56.

36. van Everdingen AA, Jacobs JW, Siewertsz Van Reesema DR, Bijlsma JW. Lowdose prednisone therapy for patients with early active rheumatoid arthritis: clinical efficacy, disease-modifying properties, and side effects: a randomized, double-blind, placebo-controlled clinical trial. Ann Intern Med. 2002;136(1):1-12.

37. Hafstrom I, Albertsson K, Boonen A, van der Heijde D, Landewe R, Svensson $B$, et al. Remission achieved after 2 years treatment with low-dose 
prednisolone in addition to disease-modifying anti-rheumatic drugs in early rheumatoid arthritis is associated with reduced joint destruction still present after 4 years: an open 2-year continuation study. Ann Rheum Dis. 2009; 68(4):508-13.

38. van Tuyl $L H$, Boers $M$, Lems WF, Landewe RB, Han $H$, van der Linden $\mathrm{S}$, et al. Survival, comorbidities and joint damage 11 years after the COBRA combination therapy trial in early rheumatoid arthritis. Ann Rheum Dis. 2010;69(5):807-12.

\section{Publisher's Note}

Springer Nature remains neutral with regard to jurisdictional claims in published maps and institutional affiliations.

- fast, convenient online submission

- thorough peer review by experienced researchers in your field

- rapid publication on acceptance

- support for research data, including large and complex data types

- gold Open Access which fosters wider collaboration and increased citations

- maximum visibility for your research: over $100 \mathrm{M}$ website views per year

At $\mathrm{BMC}$, research is always in progress. 